\title{
ChemComm
}

\section{Altered selectivity of a dipicolylamine based metal ion receptor $\dagger$}

Cite this: Chem. Commun., 2014,

50,64

Received 16th August 2013,

Accepted 22nd October 2013

DOI: $10.1039 / c 3 c c 46285 d$

www.rsc.org/chemcomm

2,2-Dipicolylamine (DPA) based receptors detect $\mathrm{Zn}^{2+}$ with high fidelity. A fluorescent sensor with thiocarbamate-linked DPA turns it into a highly selective module for $\mathrm{Ag}^{+}$with up to $\sim 7$-fold enhancement of fluorescence. The sensor exhibits a double ratiometric behavior. It also displays an interesting $\left[\mathrm{Ag}^{+}\right]$dependent aggregation induced emission.

The 2,2-dipicolylamine (DPA) unit has been the most widely used receptor for $\mathrm{Zn}^{2+}$ ions since the discovery of the Zynpyr family of fluorescent probes by the Lippard group. ${ }^{1}$ The high selectivity of the receptor was extensively studied in conjugation with various fluorophores in order to use it in aqueous media both for cell imaging and detection of $\mathrm{Zn}^{2+}{ }^{2,3}$ Yoon and Spring's group has discovered that the DPA-amide system binds to $\mathrm{Zn}^{2+}$ in a unique imidic acid tautomeric form, whereas all the other metal ions bind in the amide form. ${ }^{4} \mathrm{We}$ have frequently made use of the thiocarbamate linker to prepare a repertoire of fluorophore-spacer-receptor triads for the detection and imaging of various heavy metal ions. ${ }^{5}$ Intrigued by the unparallel fidelity and high sensitivity of DPA-amide based sensors for the $\mathrm{Zn}^{2+}$ ion, we have linked a DPA unit to a simple fluorophore through a thiocarbamate linker (Fig. 1) and studied its sensing behaviour. Here we show that the selectivity of the DPA-amide receptor is altered as a consequence of modifying the functionality: in contrast to $\mathrm{Zn}^{2+}$ selectivity of the DPA-amide unit, the DPA-thiocarbamate acts as a $\mathrm{Ag}^{+}$selective receptor. Despite its simple structure, the response of the sensor molecule to a varying amount of $\mathrm{Ag}^{+}$was rather curious.

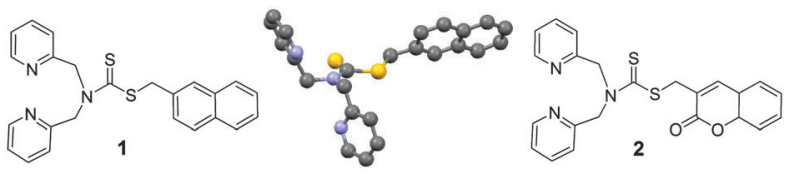

Fig. 1 Structures of 1, 2 and X-ray crystal structure of $\mathbf{1}$.

Indian Institute of Science Education and Research (IISER) Kolkata, BCKV Main Campus PO, Mohanpur, Nadia, WB 741252, India.E-mail: sb1@iiserkol.ac.in $\dagger$ Electronic supplementary information (ESI) available: Detailed characterization and additional spectroscopic details. CCDC 942550. For ESI and crystallographic data in CIF or other electronic format see DOI: 10.1039/c3cc46285d
Combining results from steady-state fluorescence, UV, NMR, dynamic light scattering, lifetime, AFM and SEM experiments, the reason for this behavior was attributed to $\mathrm{Ag}^{+}$mediated aggregation and its depletion upon addition of higher equivalents of $\mathrm{Ag}^{+}$.

Chemosensor 1 was obtained in $82 \%$ yield following our method for the synthesis of thiocarbamates starting from dipicolylamine, carbon disulphide and 2-bromomethyl naphthalene in a water-dioxane (4:1) solvent mixture. ${ }^{5}$ Details of the synthesis and characterization data, including a summary of crystallographic parameters, are provided in the ESI $\dagger$ (Fig. S15).

The emission spectra of sensor $1\left(\lambda_{\mathrm{ex}}=350 \mathrm{~nm}\right.$, Fig. S1, ESI $\left.\dagger\right)$ were recorded systematically under various conditions (Table 1). In methanol with $1 \%$ DMSO as a cosolvent, it exhibited a weak emission band (quantum yield, $\Phi=0.04$ ) at $495 \mathrm{~nm}$ (Fig. S2, ESI $\dagger$ ).

In water (with $1 \%$ DMSO as the cosolvent, $1 \mathrm{mM}$ HEPES buffered at $\mathrm{pH}=7.0$ ), the band shifted to $500 \mathrm{~nm}$ (Fig. 2D). In water-methanol $\left(\mathrm{H}_{2} \mathrm{O}-\mathrm{MeOH}, 3: 2, \mathrm{v} / \mathrm{v}\right)(1 \mathrm{mM}, \mathrm{pH}=7.0$, HEPES) the intensity of the band at $495 \mathrm{~nm}$ was found to be the highest among the varying ratios of $\mathrm{H}_{2} \mathrm{O}$ and $\mathrm{MeOH}$ (Fig. S7, ESI $\dagger$ ).

The metal-sensing ability of chemosensor $1(10 \mu \mathrm{M})$ was investigated based on its fluorescence properties in the presence of $\mathrm{Na}^{+}, \mathrm{K}^{+}$, $\mathrm{Li}^{+}, \mathrm{Mg}^{2+}, \mathrm{Co}^{2+}, \mathrm{Ni}^{2+}, \mathrm{Cu}^{2+}, \mathrm{Mn}^{2+}, \mathrm{Cr}^{3+}, \mathrm{Fe}^{3+}, \mathrm{Pb}^{2+}, \mathrm{Ag}^{+}, \mathrm{Al}^{3+}, \mathrm{Hg}^{2+}, \mathrm{Ba}^{2+}$ and $\mathrm{Zn}^{2+}(10 \mu \mathrm{M})$ salts. Initial screening with $\mathrm{MeOH}$ as the solvent gave a response with a 2.5 fold enhancement of the fluorescence signal $\left(\Phi=0.11\right.$, Fig. S2, ESI $\dagger$ ) upon addition of $\mathrm{Ag}^{+}$. In a mixed aqueous-organic solvent $\left(\mathrm{H}_{2} \mathrm{O}-\mathrm{MeOH}, 3: 2\right.$, v/v with $1 \%$ DMSO) (Table 1) the enhancement was maximum. Upon addition of the metal ions $(10 \mu \mathrm{M})$ to the receptor $1(10 \mu \mathrm{M})$, a 6.5 fold enhancement of intensity was observed ( $\Phi=0.52$ ) at $495 \mathrm{~nm}$ only with $\mathrm{Ag}^{+}$(Fig. 2A). This selectivity for $\mathrm{Ag}^{+}$remained unaltered in water (99\%).

Table 1 Fluorescent behavior of 1

\begin{tabular}{llll}
\hline Entry & Solvent $^{a}$ & $\lambda_{\text {em }}(\Phi)$ of $\mathbf{1}$ & $\lambda_{\text {em }}(\Phi)$ of $1-\mathrm{Ag}^{+}(10 \mu \mathrm{M})$ \\
\hline 1 & $\mathrm{MeOH}$ & $495(0.04)$ & $488(0.11)$ \\
2 & $\mathrm{H}_{2} \mathrm{O}-\mathrm{MeOH}(3: 2 \mathrm{v} / \mathrm{v})$ & $495(0.08)$ & $495(0.52)$ \\
3 & $\mathrm{H}_{2} \mathrm{O}$ & $500(0.06)$ & $500(0.36)$
\end{tabular}

${ }^{a} 1 \%$ DMSO or $\mathrm{CH}_{3} \mathrm{CN}, \mathrm{v} / \mathrm{v} \%$ was used as cosolvent. 


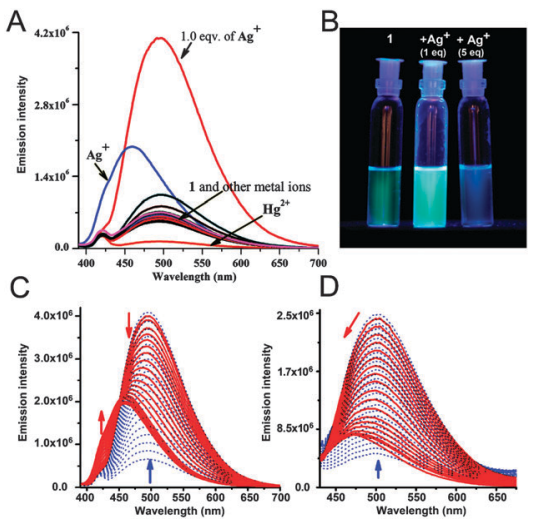

Fig. 2 (A) Change in fluorescence intensity of $1(10 \mu \mathrm{M})$ upon addition of various metal ions $(10 \mu \mathrm{M})$. The spectrum with $\mathrm{Ag}^{+}$in blue refers to the change upon addition of $50 \mu \mathrm{M} \mathrm{Ag}^{+}$in $\mathrm{H}_{2} \mathrm{O}-\mathrm{MeOH}, 3: 2, \mathrm{v} / \mathrm{v}$; (B) visual change under $366 \mathrm{~nm}$ UV light. Change in fluorescence emission of $1(10 \mu \mathrm{M})$ in $(\mathrm{C}) \mathrm{H}_{2} \mathrm{O}-$ $\mathrm{MeOH}(3: 2, \mathrm{v} / \mathrm{v})$ and (D) water (99\%) upon addition of $0-1$ equivalents (blue) and 1-5 equivalents of $\mathrm{Ag}^{+}$(red).

Among the other metal ions, $\mathrm{Hg}^{2+}$ quenched the emission intensity whereas $\mathrm{Pb}^{2+}$ showed a small enhancement of fluorescence with 1 (Fig. 2A). A discernible change was also visible with the naked eye under $366 \mathrm{~nm}$ UV light (Fig. 2B).

To gain a better insight into the fluorescence behavior, a series of experiments were carried out with a fixed concentration of chemosensor $1(10 \mu \mathrm{M})$ and a varying amount of $\mathrm{Ag}^{+}$in $\mathrm{H}_{2} \mathrm{O}-\mathrm{MeOH}$ $(3: 2, \mathrm{v} / \mathrm{v})$ for which the fluorescence response was maximum. The systematic variation of the amount of $\mathrm{Ag}^{+}$displayed a sharp enhancement of fluorescence intensity at $495 \mathrm{~nm}$ upon addition of up to 1.0 equivalent of $\mathrm{Ag}^{+}$ions, whereas at higher concentrations of $\mathrm{Ag}^{+}$ the emission intensity of $\mathbf{1}$ at $495 \mathrm{~nm}$ decreased significantly and gradually underwent a blue shift to $460 \mathrm{~nm}$ (Fig. 2C and Fig. S3A and S3B, ESI $\dagger$ ). Also, a new emission band centered at $424 \mathrm{~nm}$ was observed with a new isoemission point at $450 \mathrm{~nm}$, indicating a dualratiometric fluorescence behavior of the sensor with $\mathrm{Ag}^{+}$(Fig. S3C, ESI + ). Upon addition of 5.0 equivalents $(50 \mu \mathrm{M})$ of the metal ions, only $\mathrm{Ag}^{+}$displayed a 3 fold $(\Phi=0.25)$ enhancement of fluorescence (Fig. 2A and $\mathrm{C}$ and Fig. S3A, ESI $\dagger$ ).

This interesting behavior of the sensor at higher concentration of $\mathrm{Ag}^{+}$prompted us to explore the mechanism of the fluorescence enhancement. The time dependence of the fluorescence intensity of chemosensor $\mathbf{1}(10 \mu \mathrm{M})$ was recorded. It was found that even in the absence of any metal ions the plot of fluorescence intensity recorded at regular intervals slowly increased with time and reached a saturation level in both mixed aqueous-organic (Fig. S5, ESI $\dagger$ ) and aqueous media (Fig. S6, ESI $\dagger$ ). The maximum enhancement, found in $60 \%$ water (Fig. 3D and Fig. S7, ESI $\dagger$ ), was similar to the behavior observed for a number of rotor-like fluorescent probes studied by Tang and prompted us to hypothesize that aggregation might play a role in the enhancement of fluorescence intensity in our case as well. ${ }^{6}$ It should be noted that in all the systems where aggregation induced enhancement (AIE) of fluorescence is reported, the presence of a rotor-like biaryl framework is a common feature ${ }^{6}$ and the restriction of low energy molecular motions such as rotation of the aryl groups in the aggregated form is responsible for the enhanced emission.

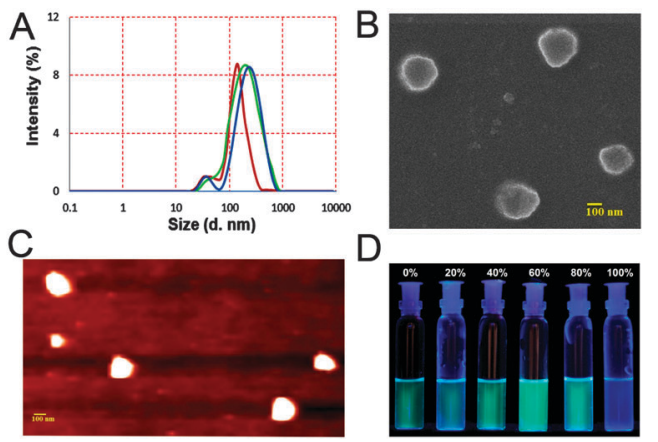

Fig. 3 (A) Particle size analysis (DLS): sample recorded after $1.5 \mathrm{~h}$ (red) and $3 \mathrm{~h}$ (green) after preparation of the solution in mixed media, and upon addition of 1 equiv. of $\mathrm{Ag}^{+}$(blue) to a freshly prepared sample of 1 in the same solvent system; (B) SEM image of the aggregates obtained after addition of $\mathrm{Ag}^{+}$(1 equiv.) to a sample of 1 and (C) the corresponding AFM image; (D) visual change observed with the change of percentage of water $(0-100 \%)$ to a $10 \mu \mathrm{M}$ solution of 1 as seen under $366 \mathrm{~nm}$ light.

The enhanced emission of $\mathbf{1}$ in highly viscous glycerol indicates that the restriction of low energy intramolecular motions plays an important role (Fig. S8, ESI $\dagger$ ). ${ }^{7}$ However, in our case, there is no biarylic rotor-like motif. This posed a basic question: whether the presence of this motif in the probes is indeed an essential criterion for the AIE. In order to investigate this, the evidence for aggregation was systematically studied under various conditions.

Addition of only one equivalent of $\mathrm{Ag}^{+}$to a freshly prepared solution of sensor $\mathbf{1}$ drastically changed the fluorescence intensity within a few seconds. In the absence of $\mathrm{Ag}^{+}$this enhancement was slow (Fig. S5 and S6, ESI $\dagger$ ). Thus, it was thought that $\mathrm{Ag}^{+}$at this concentration range acts as a mediator for the aggregation that causes an enhancement of the emission intensity. This increase in emission intensity, however, is diminished with the addition of more $\mathrm{Ag}^{+}$ions (Fig. 2A).

In our attempt to study the association of the metal-ligand binding, a clear break in the reciprocal plot was observed (Fig. S12A, ESI $\dagger$ ). This prompted us to consider the whole scenario as a stepwise bi-modal process, where the first process was a $\mathrm{Ag}^{+}$ mediated aggregation of the sensor and the second one was an interaction between a second $\mathrm{Ag}^{+}$ion and the aggregated complex which resulted in a disintegration of the aggregates. Fluorescence titration data (Fig. S3A, ESI $\dagger$ ) indicated that the metal ligand association in the first step indeed takes place in a 1:1 stoichiometry. A peak at $m / z=522$ in the ESI-MS showed the correct isotope pattern for the $1: 1$ association of $\mathrm{Ag}^{+}$with 1 (Fig. S18, ESI + ). At a lower concentration of $\mathrm{Ag}^{+}(0-10 \mu \mathrm{M})$ the binding constant was found to be $1.5 \times 10^{4} \mathrm{M}^{-1}$ (Fig. S12B, ESI $\dagger$ ) from the double reciprocal plot.

Fluorescence titration of chemosensor 1 with $\mathrm{Ag}^{+}$was also performed in aqueous medium ( $99 \%$ with $1 \%$ DMSO) in the presence of HEPES (1 mM) buffered at pH 7.0 (Fig. 2D). In aqueous medium sensor 1 showed an emission maximum at $500 \mathrm{~nm}$, however at higher concentrations of $\mathrm{Ag}^{+}$the emission band at $500 \mathrm{~nm}$ is blue shifted to $470 \mathrm{~nm}$ (Fig. S4A and S4B, ESI†). The ratiometric behavior with the additional band at $424 \mathrm{~nm}$ that was observed in $\mathrm{H}_{2} \mathrm{O}-\mathrm{MeOH}$ $(3: 2, \mathrm{v} / \mathrm{v})$ was absent in the aqueous medium (Fig. 2D).

The leveling of the tail at a higher wavelength in the UV-vis spectra of $1(10 \mu \mathrm{M})$ in the presence and absence of 1 equivalent of 
$\mathrm{Ag}^{+}$ions was consistent with our hypothesis of the formation of aggregates. With the addition of more $\mathrm{Ag}^{+}$, this leveling-off of the tail diminished and coincided with the baseline indicating that the aggregates dissolved at higher concentrations of $\mathrm{Ag}^{+}$(Fig. S9A, ESI $\dagger$ ).

The silver assisted aggregation was further confirmed by ${ }^{1} \mathrm{H}$ NMR titration experiments in $\mathrm{CD}_{3} \mathrm{OD}-\mathrm{D}_{2} \mathrm{O}(1: 1, \mathrm{v} / \mathrm{v})$ (Fig. S11, ESI $\dagger$ ). The NMR spectrum of 1 without any added metal ion and upon addition of $\mathrm{Ag}^{+}$ions (up to 1.0 equiv.) showed a somewhat poor signal quality that is often encountered with aggregated samples. Additionally, significant up-field shifts of several aromatic protons compared to the one in pure $\mathrm{MeOH}$ are strongly indicative of the formation of aggregates under these conditions. ${ }^{8}$ However, further addition of $\mathrm{Ag}^{+}$ $(>1.0$ equiv.) to the same solution produced sharp spectra with reduced line broadening with a significant downfield shift of aromatic and methylene protons, indicating the depletion of the aggregates. Additionally, the downfield shifts of the methylene protons adjacent to the pyridyl and thiocarbamate units indicate that the binding to $\mathrm{Ag}^{+}$involves both the moieties. Mass spectrometry of a sample of $\mathbf{1}$ with five equivalents of $\mathrm{Ag}^{+}$showed a peak at $m / z 666$ corresponding to the species $\left[\mathbf{1}+2 \mathrm{Ag}+\mathrm{H}_{2} \mathrm{O}+\mathrm{OH}^{-}\right]$ indicating the binding of two $\mathrm{Ag}^{+}$ions (Fig. S19, $\mathrm{ESI} \dagger$ ). Thus, the binding of 1 to $\mathrm{Ag}^{+}$is dependent on the concentration of the metal ion and is consistent with our suggested bimodal model.

DLS experiments (Fig. 3A and Fig. S14A, ESI $\dagger$ ) agreed well with our hypothesis. The time dependent particle size distribution of a sample of $1(10 \mu \mathrm{M})$ in mixed media increased over time (Fig. 3A). Addition of 1 equiv. $\mathrm{Ag}^{+}$promoted fast aggregation. Thus, the $Z$-average diameter of $192( \pm 7) \mathrm{nm}(\mathrm{PDI}=0.33)$ of the aggregates recorded after $1.5 \mathrm{~h}$ increased to $239( \pm 11) \mathrm{nm}(0.39)$ (Fig. 3A) after $3 \mathrm{~h}$. Upon addition of 1 equivalent of $\mathrm{Ag}^{+}$to a freshly prepared sample, the diameter was found to be $248( \pm 8) \mathrm{nm}(0.31)$ (Fig. 3A). Addition of 5 equivalents of $\mathrm{Ag}^{+}$resulted in a gradual dissolution of the aggregates and the particle size became too small to determine by DLS. The AFM and the SEM (Fig. 3B and C) results obtained with $1(10 \mu \mathrm{M})$ in the presence and absence of $\mathrm{Ag}^{+}$( 1 equiv.) were also in good agreement with the previous data. The particle diameter obtained with AFM and SEM was $215( \pm 19) \mathrm{nm}$ and $220 \mathrm{~nm}$ respectively.

In the crystal structure, two consecutive naphthyl rings of $\mathbf{1}$ are aligned in a parallel-displaced or offset arrangement at a distance of $4.3 \AA$, perhaps to minimize the dispersion forces (Fig. S16, ESI $\dagger$ ). ${ }^{9}$ It is conceivable that in the aggregates such stacking of the aromatic units may also take place. This is important since face-to-face $\pi$-stacking interactions would have disrupted the fluorescence. ${ }^{10}$

Lifetime studies described in the ESI $\dagger$ were consistent with the proposed model of formation and depletion of the aggregates (Fig. S14B and Table S1, ESI $\dagger$ ). Fahrni has recently observed that the break-down of aggregates of a probe upon complexation of $\mathrm{Cu}(\mathrm{I})$ enhances fluorescence. ${ }^{11}$

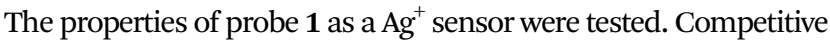
experiments were carried out with the chemosensor and $\mathrm{Ag}^{+}$in the presence of various metal ions (Fig. S9B, ESI $\dagger$ ). The results clearly indicated that the fluorescence response of the chemosensor is affected only in the presence of $\mathrm{Hg}^{2+}$ where the fluorescence intensity is quenched, whereas no significant change in the fluorescence response was observed for the other metal ions. The emission of $\mathbf{1}$ in the presence of one equivalent of $\mathrm{Ag}^{+}$observed between $\mathrm{pH} 3$ and 12 clearly indicates that the sensor can detect the $\mathrm{Ag}^{+}$ions over a broad $\mathrm{pH}$ range (Fig. S10, ESI $\dagger$ ). The detection limit determined using standard methods from the fluorescence data collected at low concentrations of $\mathrm{Ag}^{+}$was found to be $83 \mathrm{nM}$ (Fig. S13, ESI $\dagger$ ).

In conclusion, we have shown that the selectivity of a DPA based receptor can be tuned to bind $\mathrm{Ag}^{+}$upon modification with a thiocarbamate linkage. The probe shows a high selectivity and sensitivity for $\mathrm{Ag}^{+}$metal ions. The presence of the aromatic ring gave rise to stacking of the molecules, thereby forming aggregates. In the aggregated state, the enhanced emission of the probe is due to the restriction of intramolecular flexibility and rotation. The formation of the aggregates was promoted by addition of up to one equivalent of $\mathrm{Ag}^{+}$, whereas the metal ion at a higher concentration led to disintegration of the aggregates. From these detailed studies, we conclude that aggregation induced enhancement can occur even in systems devoid of any rotor-like motif. These interesting results warranted the preparation of more probes with the DPA-thiocarbamate scaffold and the study of their sensing properties. In fact, on advice of a reviewer, we have synthesized compound 2 (Fig. 1) with a coumarin fluorophore (characterization: Fig. S26-S28, ESI $\dagger$ ) that shows a similar sensing and AIE behavior (Fig. S20-S23, ESI $\dagger$ ).

The help of Mr Arnab Maity with AFM studies and of Mr Soumik Mondal with crystallography is gratefully acknowledged. We thank the CSIR for a fellowship to JH, IISER for facilities and DST for a research grant (SR/S1/OC-26/2010).

\section{Notes and references}

1 G. K. Walkup, S. C. Burdette, S. J. Lippard and R. Y. Tsien, J. Am. Chem. Soc., 2000, 122, 5644.

2 (a) S. C. Burdette, G. K. Walkup, B. Spingler, R. Y. Tsien and S. J. Lippard, J. Am. Chem. Soc., 2001, 123, 7831; (b) C. C. Woodroofe and S. J. Lippard, J. Am. Chem. Soc., 2003, 125, 11458; (c) C. J. Chang, E. M. Nolan, J. Jaworski, S. C. Burdette, M. Sheng and S. J. Lippard, Chem. Biol., 2004, 11, 203.

3 (a) S. Atilgan, T. Ozdemir and E. U. Akkaya, Org. Lett., 2008, 10, 4065; (b) W. Jiang, Q. Fu, H. Fan and W. Wang, Chem. Commun., 2008, 259; (c) B. Tang, H. Huang, K. Xu, L. Tong, G. Yang, X. Liu and L. An, Chem. Commun., 2006, 3609; (d) H. T. Ngo, X. Liu and K. A. Jolliffe, Chem. Soc. Rev., 2012, 41, 4928; (e) S. Maruyama, K. Kikuchi, T. Hirano, Y. Urano and T. Nagano, J. Am. Chem. Soc., 2002, 124, 10650.

4 Z. C. Xu, J. Yoon and D. R. Spring, Chem. Soc. Rev., 2010, 39, 1996.

5 For example: (a) J. Hatai, S. Pal, G. P. Jose and S. Bandyopadhyay, Inorg. Chem., 2012, 51, 10129; (b) J. Hatai, S. Pal, G. P. Jose, T. Sengupta and S. Bandyopadhyay, RSC Adv., 2012, 2, 7033.

6 (a) Z. Chang, Y. Jiang, B. He, J. Chen, Z. Yang, P. Lu, H. S. Kwok, Z. Zhao, H. Qiu and B. Z. Tang, Chem. Commun., 2013, 49, 594; (b) Y. Hong, J. W. Y. Lam and B. Z. Tang, Chem. Commun., 2009, 4332; (c) Y. Hong, J. W. Y. Lam and B. Z. Tang, Chem. Soc. Rev., 2011, 40, 5361; (d) W. Z. Yuan, S. Chen, J. W. Y. Lam, C. Deng, P. Lu, H. H.-Y. Sung, I. D. Williams, H. S. Kwok, Y. Zhang and B. Z. Tang, Chem. Commun., 2011, 47, 112161; (e) J. Liu, Q. Meng, X. Zhang, X. Lu, P. He, L. Jiang, H. Dong and W. Hu, Chem. Commun., 2013, 49, 1199.

7 (a) M. A. Haidekker and E. A. Theodorakis, Org. Biomol. Chem., 2007, 5, 1669; (b) V. Bhalla, S. Kaur, V. Vij and M. Kumar, Inorg. Chem., $2013,52,4860$.

8 (a) N. Maurer, K. F. Wong, M. J. Hope and P. R. Cullis, Biochim. Biophys. Acta, 1998, 1374, 9; (b) I. Turcu and M. Bogdan, J. Phys. Chem. B, 2012, 116, 6488.

9 (a) T. Janowski and P. Pulay, J. Am. Chem. Soc., 2012, 134, 17520; (b) C. R. Martinez and B. L. Iverson, Chem. Sci., 2012, 3, 2191.

10 J. B. Birks, Photophysics of Aromatic Molecules, Wiley, New York, 1970.

11 M. T. Morgan, P. Bagchi and C. J. Fahrni, J. Am. Chem. Soc., 2011, 133, 15906. 